\title{
Coping with the calcium overload caused by cell injury: ER to the rescue
}

\author{
Goutam Chandra ${ }^{1,2}$, Davi A. G. Mázala ${ }^{1,3}$ and Jyoti K. Jaiswal ${ }^{1,4, *}$ \\ ${ }^{1}$ Center of Genetic Medicine Research, Children's National Research Institute, 111 Michigan Av NW, Washington, DC 20010, Wash- \\ ington, DC. \\ 2 Inter University Centre for Biomedical Research \& Super Specialty Hospital, Mahatma Gandhi University Campus at Thalappady, \\ Kottayam, Kerala, India. \\ ${ }^{3}$ Department of Kinesiology, College of Health Professions, Towson University, Maryland, U.S.A. \\ ${ }^{4}$ Department of Genomics and Precision Medicine, George Washington University School of Medicine and Health Sciences, Washing- \\ ton, DC. \\ * Corresponding Author: \\ Jyoti K Jaiswal, Center of Genetic Medicine Research, Children's National Research Institute, 111 Michigan Av NW, Washington, \\ DC 20010, Washington, DC; E-mail: jkjaiswal@cnmc.org
}

Cells maintain their cytosolic calcium $\left(\mathrm{Ca}^{2+}\right)$ in nanomolar range and use controlled increase in $\mathrm{Ca}^{2+}$ for intracellular signaling. With the extracellular $\mathrm{Ca}^{2+}$ in the millimolar range, there is a steep $\mathrm{Ca}^{2+}$ gradient across the plasma membrane (PM). Thus, injury that damages PM, leads to a cytosolic $\mathrm{Ca}^{2+}$ overload, which helps activate PM repair (PMR) response. However, in order to survive, the cells must cope with the $\mathrm{Ca}^{2+}$ overload. In a recent study (Chandra et al. J Cell Biol,doi: 10.1083/jcb.202006035) we have examined how cells cope with injury-induced cytosolic $\mathrm{Ca}^{2+}$ overload. By monitoring $\mathrm{Ca}^{2+}$ dynamics in the cytosol and endoplasmic reticulum (ER), we found that PM injurytriggered increase in cytosolic $\mathrm{Ca}^{2+}$ is taken up by the ER. Pharmacological inhibition of ER $\mathrm{Ca}^{2+}$ uptake interferes with this process and compromises the repair ability of the injured cells. Muscle cells from patients and mouse model for the muscular dystrophy showed that lack of Anoctamin 5 (ANO5)/Transmembrane protein 16E (TMEM16E), an ER-resident putative $\mathrm{Ca}^{2+}$ activated chloride channel ( $\mathrm{CaCC})$, are poor at coping with cytosolic $\mathrm{Ca}^{2+}$ overload. Pharmacological inhibition of $\mathrm{CaCC}$ and lack of ANO5, both prevent $\mathrm{Ca}^{2+}$ uptake into ER. These studies identify a requirement of $\mathrm{Cl}^{-}$uptake by the ER in sequestering injury-triggered cytosolic $\mathrm{Ca}^{2+}$ increase in the ER. Further, these studies show that ER helps injured cells cope with $\mathrm{Ca}^{2+}$ overload during PMR, lack of which contributes to muscular dystrophy due to mutations in the ANO5 protein.
It was nearly a century ago that Lewis Victor Heilbrunn identified the requirement of extracellular $\mathrm{Ca}^{2+}$ for what he termed as 'surface precipitation reaction', a process that allows the cytoplasm streaming out from an injured cell to coagulate. Studies since then have identified that entry of extracellular $\mathrm{Ca}^{2+}$ into the injured cells trigger vesicle fusion, membrane remodeling, and cytoskeletal reorganization, all of which are required to repair the PM of the injured cell. While it is well recognized that excess cytosolic $\mathrm{Ca}^{2+}$ causes cell death, there is little understanding of how cells handle the large amount of extracellular $\mathrm{Ca}^{2+}$ that enters the injured cell. Being the largest membrane bound organelle and the major site for storing intracellular $\mathrm{Ca}^{2+}$, the ER is likely to aid in coping with the cytosolic $\mathrm{Ca}^{2+}$ overload. In a recent study, we used an ER-targeted $\mathrm{Ca}^{2+}$ sensor and found that ER responds to PM injury by rapidly sequestering the extracellular $\mathrm{Ca}^{2+}$ that enters the injured cell. This uptake of $\mathrm{Ca}^{2+}$ by the ER was mediated by the sarco/endoplasmic reticulum $\mathrm{Ca}^{2+}$-ATPase (SERCA) - the ER resident pump required for cytosolic $\mathrm{Ca}^{2+}$ uptake into the ER. Inhibition of SERCA activity in injured cells through a pharmacological inhibitor (thapsigargin), prevented $\mathrm{ER} \mathrm{Ca}^{2+}$ uptake. Concomitantly, this also impaired the ability of the injured cells to sequester the cytosolic $\mathrm{Ca}^{2+}$, and impaired PMR. While this identified the role of ER in the injured cell's ability to cope with $\mathrm{Ca}^{2+}$ influx, it raised two additional questions:

(1) What is the mechanism by which ER senses and buffers increased cytosolic $\mathrm{Ca}^{2+}$ ?

(2) Why does failure to buffer cytosolic $\mathrm{Ca}^{2+}$ result in poor repair of the injured cell?

MICROREVIEW on: Chandra G, Sreetama SC, Mázala DAG, Charton K, VanderMeulen JH, Richard I, Jaiswal JK (2021). Endoplasmic reticulum maintains ion homeostasis required for plasma membrane repair. J Cell Biol 220(5): e202006035. doi: 10.1083/jcb.202006035. 
The answer to the first question is confounded by the fact that SERCA activity is not regulated by the cytosolic $\mathrm{Ca}^{2+}$ level. Instead, sustaining SERCA-mediated ER Ca ${ }^{2+}$ uptake requires the lumen of the ER to be kept electroneutral through the export of $\mathrm{H}^{+}$and import of negatively charged ions such as Chloride $\left(\mathrm{Cl}^{-}\right)$. Previously, we had observed that cells from Limb Girdle Muscular Dystrophy 2L (LGMD2L) patients, repair poorly due to lack of an ERlocalized putative $\mathrm{Ca}^{2+}$ activated chloride channel (CaCC) protein - Anoctamin 5 (ANO5) also called Transmembrane 16E (TMEM16E). If injury-triggered increase in cytosolic $\mathrm{Ca}^{2+}$ activates ANO5-mediated pumping of $\mathrm{Cl}^{-}$ions into the $E R$, then this could be the mechanism for the activation of $\mathrm{Ca}^{2+}$ uptake by the ER in healthy cells. In our recent study we found that similar to thapsigargin-treated healthy cells, LGMD2L patient cells are also poor at coping with injurytriggered increase in the cytosolic $\mathrm{Ca}^{2+}$. Through the use of a ER-targeted anion sensor, our study identified that PM injury led to anion uptake into the ER, which is compromised by NPPB (5-nitro-2-(3-phenylpropyl-amino) benzoic acid) - an inhibitor of CaCC. Similar to NPPB treated healthy cells, anion uptake into the ER was compromised in the injured LGMD2L patient cells. Concomitantly, the ER of the NPPB treated healthy cells and of the LGMD2L patient cells were both compromised in their ability to uptake injurytriggered increase in cytosolic $\mathrm{Ca}^{2+}$. By using a ANO5 knockout mouse, we examined $\mathrm{Ca}^{2+}$ homeostasis in injured ANO5-deficient muscle fibers, which identified that ANO5deficient fibers are compromised in their ability to cope with the injury-triggered $\mathrm{Ca}^{2+}$ overload and in repairing PM damaged by focal injury or mechanical activity. Together, above results identify that cytosolic $\mathrm{Ca}^{2+}$ increase in injured cells triggers ER-resident CaCC activity, which supports clearance of cytosolic $\mathrm{Ca}^{2+}$ by the ER (Figure 1). This mechanism is the basis for the ER Ca ${ }^{2+}$ uptake in the injured cells and ANO5/TMEM16E is the CaCC that supports ERmediated clearance of cytosolic $\mathrm{Ca}^{2+}$ overload in injured muscle cells.

Given the requirement of $\mathrm{Ca}^{2+}$ increase for PMR, the next question was why does failure to rapidly buffer cytosolic $\mathrm{Ca}^{2+}$ compromise the ability of the injured cell to repair. The answer came from examining (A) Annexinmediated PMR, and (B) Mitochondria-mediated PMR. Based on the $\mathrm{Ca}^{2+}$ affinity of the different annexins, PM injury causes sequential recruitment and clearance of annexins at the injury site. This injury-triggered dynamics of annexins is required for remodeling and repair of the injured PM. ANO5 deficit in the LGMD2L patient cells altered the injury-triggered dynamics of two of the annexin proteins we examined - Annexin A1 and Annexin A2. While both these annexins were recruited to the site of injury in patient cells at the kinetics similar to the healthy cells, prolonged cytosolic $\mathrm{Ca}^{2+}$ increase in patient cells correlated with the failure of annexins to clear from the injury site, interfering with annexin-mediated PMR. Another PMR pathway is mediated by the injury-proximal mitochondria, which helps clear some of the cytosolic $\mathrm{Ca}^{2+}$, but also get depolarized and increases reactive oxygen species (ROS) production. ROS from these mitochondria then activates local buildup of actin cytoskeleton that helps close the PM

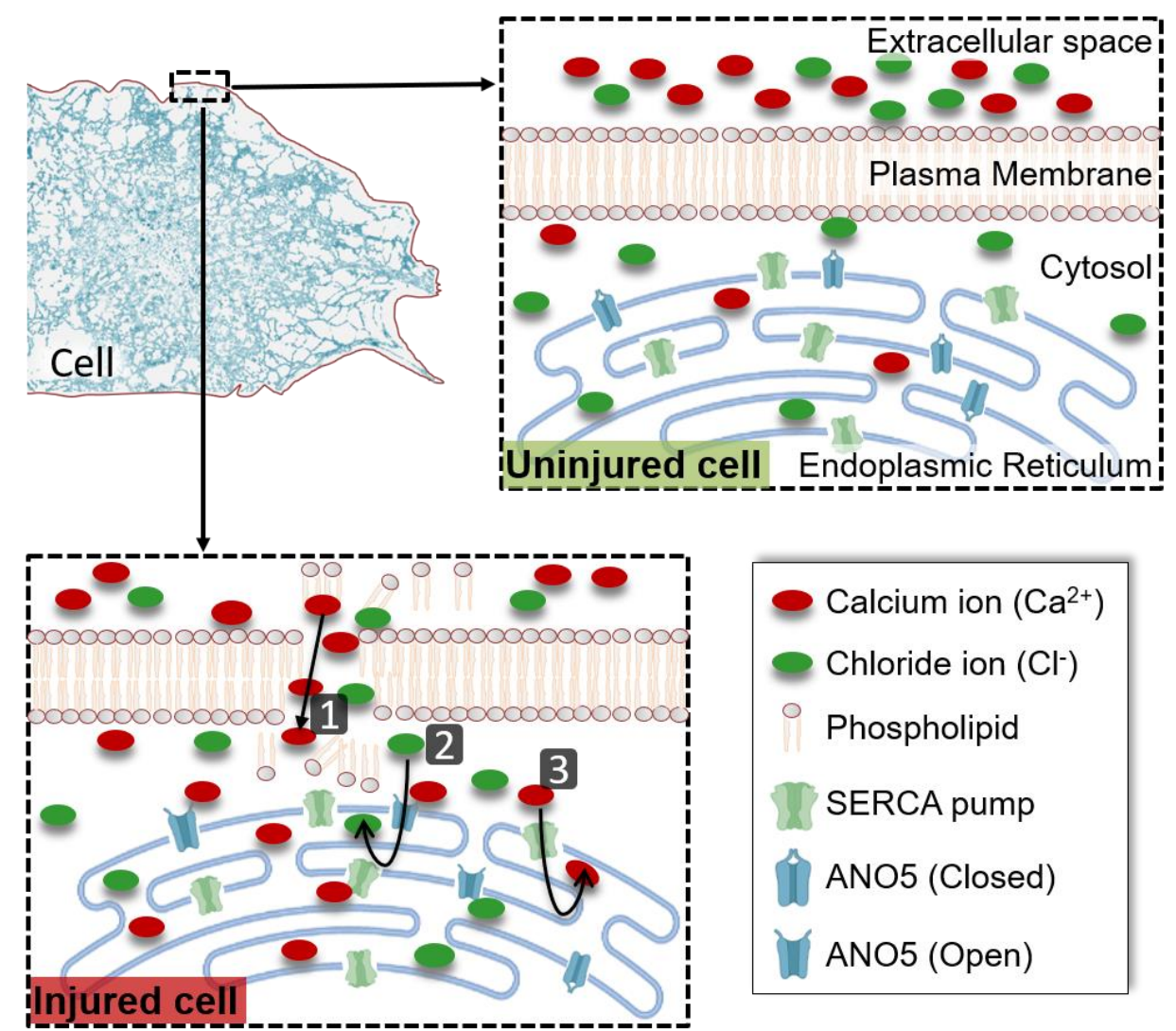

FIGURE 1: ER-mediated buffering of injury-triggered cytosolic $\mathrm{Ca}^{2+}$ increase. Plasma membrane acts as a barrier to maintain cytosolic ion balance, which is disrupted by cell injury leading to influx of ions such as $\mathrm{Ca}^{2+}(1)$. This increase in cytosolic $\mathrm{Ca}^{2+}$ activates opening of the ERresident ion channel ANO5 and increases influx of the $\mathrm{Cl}^{-}$ions into the ER lumen (2). This $\mathrm{Cl}^{-}$ion serves as the counterion to maintain ER electroneutrality as the excess cytosolic $\mathrm{Ca}^{2+}$ is pumped into the ER lumen by the ERresident $\mathrm{Ca}^{2+}$ pump SERCA (3). Together, these transporters enable buffering the cytosolic $\mathrm{Ca}^{2+}$ overload caused by PM injury, and their inhibition prevents clearance of cytosolic $\mathrm{Ca}^{2+}$ increase in the injured cell, compromising repair of the injured cell. 
wound. Injury of patient cells lacking ANO5 increased $\mathrm{Ca}^{2+}$ uptake and caused extensive depolarization of their mitochondria, impairing mitochondria-mediated PMR. Based on these findings we concluded that failure of ER to sequester injury-triggered increase in cytosolic $\mathrm{Ca}^{2+}$ impairs spatial and temporal regulation of PMR response, which compromises the ability of these cells to repair. This indicated that approaches to restore cytosolic $\mathrm{Ca}^{2+}$ balance in the injured ANO5 deficient cells could improve their repair ability. Accordingly, our study identified improved repair of ANO5 knockout muscle fibers treated with a cell permeant $\mathrm{Ca}^{2+}$ chelator - BAPTA-AM (1,2-bis(o-aminophenoxy) ethane$\mathrm{N}, \mathrm{N}, \mathrm{N} 9, \mathrm{~N} 9$-tetraacetic acid- acetoxy-methyl ester).

Together, these results highlight the Goldilocks-like nature of injury-triggered $\mathrm{Ca}^{2+}$ increase, such that too little or too much increase both compromise PMR. It shows that ER-mediated cytosolic $\mathrm{Ca}^{2+}$ uptake allows the control over the amplitude and time of cytosolic $\mathrm{Ca}^{2+}$ increase in the injured cells. It highlights that $\mathrm{Ca}^{2+}$ uptake by the ER in injured cell relies upon $\mathrm{Ca}^{2+}$-activated anion transport and failure of anion or $\mathrm{Ca}^{2+}$ uptake by the ER disrupts the fine balance of multiple PMR repair responses mounted by the cell, compromising the cell's repair ability. Identification of this ER-mediated $\mathrm{Ca}^{2+}$ and PMR regulation not only identifies a new role for this organelle, but also offer insights into how defect in a putative anion channel can cause poor muscle repair in LGMD2L patients and point to future avenues for its therapy.

\section{ACKNOWLEDGMENTS}

GC acknowledges support by Ramalingaswami fellowship by Department of Biotechnology, Government of India, and JKJ and DAG acknowledge grants by the National Institute of Arthritis and Musculoskeletal and Skin Diseases (R01AR055686, T32AR056993) and the National Institute of Child Health and Human Development (R21HD103993, and U54HD090257).

\section{CONFLICT OF INTEREST}

Authors have no competing financial interests.

\section{COPYRIGHT}

(C) 2021 Chandra et al. This is an open-access article released under the terms of the Creative Commons Attribution (CC BY) license, which allows the unrestricted use, distribution, and reproduction in any medium, provided the original author and source are acknowledged.

Please cite this article as: Goutam Chandra, Davi A. G. Mázala and Jyoti K. Jaiswal (2021). Coping with the calcium overload caused by cell injury: ER to the rescue. Cell Stress 5(5): 73-75. doi: 10.15698/cst2021.05.249 